\title{
Is the prevalence of dehydration among community-dwelling older adults really low? Informing current debate over the fluid recommendation for adults aged $70+$ years
}

\author{
Jodi Dunmeyer Stookey*, Carl F Pieper and Harvey Jay Cohen \\ Center for the Study of Aging and Human Development, Claude D Pepper Older Americans Independence Center, \\ Duke University Medical Center, Box 3003, Durham, NC 27710, USA and the Geriatric Research, Education and \\ Clinical Center (GRECC), Veterans Administration Medical Center, Durham, NC, USA
}

Accepted 19 August 2003

\begin{abstract}
Objective: The fluid recommendation for adults aged $70+$ years has been criticised on the basis of a low prevalence of dehydration in community-dwelling older adults. This study explores whether the low prevalence might reflect limitations of individual dehydration indices.

Design: Cross-sectional data on plasma sodium, blood urea nitrogen (BUN), creatinine, glucose and potassium were used to classify 1737 participants of the 1992 Established Populations for Epidemiologic Studies of the Elderly (EPESE) (70+ years) according to multiple dehydration indices. Associations between dehydration indices, health and functional status were evaluated.

Results: Depending on the indicator used, the prevalence of dehydration ranged from $0.5 \%$ for hypotonic hypovolaemia only (plasma tonicity $<285 \mathrm{mOsml}^{-1}$ with orthostatic hypotension) to $60 \%$ with dehydration defined as either plasma sodium $\geq 145 \mathrm{mEq}^{-1}$, BUN/creatinine ratio $\geq 20$, tonicity $\geq 295 \mathrm{mOsml}^{-1}$, or hypotonic hypovolaemia. Elevated tonicity and $\mathrm{BUN} / \mathrm{creatinine}$ ratio were respectively associated with chronic disease and functional impairment.

Conclusions: The true prevalence of dehydration among community-dwelling adults may be low or high, depending on the indicator(s) used to define dehydration. Before we can pinpoint a generalisable prevalence of dehydration for community-dwelling seniors and draw conclusions about fluid recommendations, validation studies of dehydration indices and longitudinal studies of dehydration, health and functional status are needed.
\end{abstract}

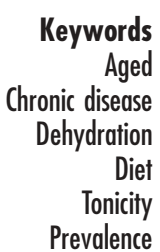

General consensus that ageing-related changes in physiology, behaviour, health and functional status predispose all older adults to dehydration ${ }^{1-7}$ has motivated dietary guidelines for older adults that emphasise fluid intake. Unlike the Food Guide Pyramid for younger adults 8 , the Modified Pyramid for $70+$ Adults includes a visual representation of glasses of water at its base. The guidelines recommend that older adults consume 8 glasses (2 quarts or litres) of fluid per day 9 .

Despite consensus that older adults are at increased risk of dehydration, the fluid recommendation sparked debate because available data suggest that only institutionalised elders actually become dehydrated. While studies pertaining to samples of hospitalised patients or long-term care residents report prevalences as high as $80 \%$ (e.g. references 7, 10 and 11), the few studies of community-dwelling older adults indicate prevalences of only $0-10 \%{ }^{12-14}$. Lindeman et $a l^{13}$ argue that if only the frail and infirm are at risk of dehydration, then the fluid recommendation may be inappropriately high, unnecessarily aggravating problems of incontinence and/or risk of water overload.

Although the prevalence of dehydration in communitydwelling older adults should inform fluid recommendations, currently available prevalence estimates may not be useful for this purpose. The currently available estimates focus on specific forms of dehydration ${ }^{12-14}$ and do not reflect overall hydration status. As no single measure captures all possible forms of dehydration ${ }^{15,16}$, no single measure completely discriminates between dehydrated and non-dehydrated persons.

Using multiple indices of dehydration from the Established Populations for Epidemiologic Studies of the Elderly (EPESE), in the present paper we estimate the prevalence of several forms of dehydration, and report a range of possible estimates for an overall prevalence of dehydration. Given the non-specific nature of the 
available indices, additional data are reported to help distinguish between dehydration and other fluid disorders. Considering the argument that dehydration only occurs with illness or frailty ${ }^{13}$, we also present associations between fluid status and sociodemographic, health and functional status.

\section{Materials and methods}

\section{Sample}

Data from the Duke component of the National Institute on Aging-funded EPESE were used for this analysis. As reported previously, 4162 subjects aged 65 years and older were selected as a random household sample from North Carolina in $1986^{17}$. Blacks were over-sampled. The cohort was re-interviewed in 1992, and blood samples drawn from all subjects able to consent and who agreed to the blood draw. The study was approved by the Duke University School of Medicine Institutional Review Board for the protection of human subjects.

In $1992,1281(30.8 \%)$ of the original cohort had died, while $314(7.5 \%)$ refused to participate, were shielded or lost to follow-up. Of those remaining, 2314 were eligible to give blood, 414 were shielded or refused, and 117 had moved away. Phlebotomists were unable to obtain blood from 29 persons. Necessary laboratory measures were missing for five persons. The present analysis focused on whites and blacks $(n=1737)$, excluding 13 of other race/ethnicity. The study sample was significantly younger, and less cognitively and functionally impaired than those unable or unwilling to consent for the blood draw $^{17}$

\section{Blood collection and laboratory methods}

Trained phlebotomists drew blood at the convenience of each subject. The majority of subjects completed the blood draw within 4 months of the interview (92\%), after 09.00 hours (99\%) or after 10.00 hours (90\%). The blood was collected in tubes containing ethylenediaminetetraacetic acid as well as non-anticoagulated Vacutainer tubes, placed on ice for travel to the laboratory, and immediately processed at the Duke OB/GYN Endocrinology Laboratory (Durham, NC, USA). Plasma was frozen and stored at $-70^{\circ} \mathrm{C}$. As reported previously ${ }^{18}$, plasma interleukin (IL)-6 was measured by enzyme-linked immunosorbent assay. Serum was separated and sent refrigerated by air courier to Nichols Laboratory (San Diego, CA, USA) where determinations of glucose, potassium and sodium were completed within $24 \mathrm{~h}$.

\section{Debydration indices}

Given the variety of possible types of dehydration ${ }^{15,16}$, we defined dehydration in terms of several commonly used clinical indicators: plasma blood urea nitrogen (BUN)/ creatinine ratio, sodium, orthostatic blood pressure, and tonicity (effective plasma osmolarity). Each indicator may reflect a particular facet of hydration status. In the absence of renal dysfunction, the plasma BUN/creatinine ratio indexes hydration status relative to protein metabolism. Plasma sodium indexes hydration status relative to salt load. Plasma tonicity reflects cellular hydration status, the relative distribution of body water between the intra- and extracellular compartments. Plasma tonicity was estimated following $\mathrm{Matz}^{19}$ as: $[2 \times($ plasma sodium + plasma potassium $)]+($ plasma glucose $) / 18$, with sodium and potassium in units of $\mathrm{mEql}^{-1}$ and glucose in units of $\mathrm{mg} \mathrm{dl}^{-1}$. We chose normal ranges for plasma sodium $\left(137-145 \mathrm{mmoll}^{-1}\right)$, BUN/creatinine ratio $(<20)$ and tonicity $\left(285-295 \mathrm{mOsm}^{-1}\right)$ consistent with the literature ${ }^{6,7,10-13,19}$, distinguishing between mild (295$300 \mathrm{mOsm}^{-1}$ ) and overt hypertonicity $\left(300 \mathrm{mOsm} \mathrm{l}^{-1}\right.$ or higher). Hypotonic hypovolaemic dehydration was defined as plasma tonicity less than $285 \mathrm{mOsml}^{-1}$ with changes in diastolic blood pressure from sitting to standing of $10 \mathrm{mmHg}$ or more. We evaluated each criterion alone, and then the criteria combined. Subjects with normal plasma BUN/creatinine, tonicity and sodium values were considered non-dehydrated.

\section{Covariates}

The continuous plasma BUN, creatinine, sodium, glucose, potassium and albumin variables were categorised using standard normal range cut-offs. Given the non-fasting nature of the blood samples, plasma glucose was evaluated relative to the American Diabetes Association ${ }^{20}$ cut-off for abnormally elevated blood glucose following a 2-hour oral glucose tolerance test. Body mass index (BMI) $\left(\mathrm{kg} \mathrm{m}^{-2}\right)$ was calculated from measured height and weight for all but 263 subjects, and used to classify subjects as underweight (BMI $<18.5 \mathrm{~kg} \mathrm{~m}^{-2}$ ), normal-weight (BMI $\geq 18.5$ to $<25.0 \mathrm{~kg} \mathrm{~m}^{-2}$ ), overweight (BMI $\geq 25.0$ to $<30.0 \mathrm{~kg} \mathrm{~m}^{-2}$ ) or obese (BMI $\left.\geq 30.0 \mathrm{~kg} \mathrm{~m}^{-2}\right)^{21}$. Plasma IL$6\left(\geq 5 \mathrm{pg} \mathrm{ml}^{-1}\right)$ was an available indicator of chronic inflammation for 1708 subjects. All but 21 subjects reported whether a doctor had ever told them they had cancer, heart disease, stroke, diabetes and/or hypertension. Multiple co-morbidity was defined as reporting two or more chronic conditions. Information about polypharmacy (use of two or more prescription medications) was available for all but three subjects. The RosowBreslau index of functional ability ${ }^{22}$ was available for all but 54 subjects.

\section{Statistical analyses}

All analyses were conducted using Intercooled Stata $6.0^{23}$. Weighted estimates of the prevalence of dehydration and non-dehydration were determined. Age-, sex- and racespecific weighted prevalence estimates were predicted from multinomial logistic regression models with fluid status as outcome and age, sex and race as independent 
variables. Dehydration classifications based on tonicity, BUN/creatinine and plasma sodium were compared, and the agreement between 'dehydrated/not dehydrated' evaluated using the kappa statistic.

Given prevalences of hypovolaemia and hypernatraemia below 5\%, the following analyses focused on tonicity and BUN/creatinine status only. To evaluate whether the indices might reflect disorders other than underhydration, the fluid status groups were described in terms of plasma glucose, potassium, creatinine, BUN, albumin and haematocrit. To evaluate whether the indices covaried with disease status, the relative odds of reporting multiple chronic co-morbidities, cancer, heart disease, stroke, diabetes, hypertension, elevated plasma IL-6, poly-pharmacy, underweight, overweight or obese status and functional impairment were estimated for each group. Between-group differences were evaluated using multinomial logistic regression or logistic regression models with each categorical blood variable or health outcome as dependent variable and fluid status as main exposure. Hypertonic subjects were compared with normotonic subjects. Individuals with an elevated BUN/creatinine ratio were compared with subjects with a normal BUN/creatinine value. Given that each reference group might include dehydrated subjects, the fluid status groups were also compared with subjects classified as non-dehydrated according to both indices. All models adjusted for survey design effects, age, sex and race. The 95\% confidence intervals (CI) and tests for statistical significance were based on robust standard errors. Between-group differences with a probability below 0.05 were considered statistically significant.

Multivariable models evaluating BUN/creatinine controlled for plasma creatinine a marker of renal function. When renal function is normal, a high plasma BUN suggests insufficient body water for excretion of nitrogenous waste. When renal function is abnormal, both BUN and creatinine values may be elevated. Although the ratio measure takes renal status into account for each individual, it does not hold constant the level of renal function across individuals. Since renal function may be associated with the sociodemographic and other health status variables examined in this analysis, we controlled for plasma creatinine in the multivariable models to facilitate interpretation of observed BUN/creatinine effects.

\section{Results}

Descriptive statistics are shown in Tables 1 and 2. The sample was predominantly female, between the ages of 70 and 84 years, and roughly equally distributed between blacks and whites. Hypertension, some degree of functional limitation and overweight status affected over half of the sample. Chronic disease co-morbidity was reported by $42 \%$ of subjects. The mean blood chemistry values were within the normal ranges for all measures except plasma glucose, which appeared elevated, and haematocrit, which appeared depressed.

The prevalence of elevated plasma BUN/creatinine, plasma tonicity and plasma sodium appeared to increase with age. Females and whites had significantly lower mean creatinine levels and higher mean BUN/creatinine ratios than males and blacks, respectively. Blacks had significantly higher plasma sodium, glucose and tonicity values than whites.

Unweighted prevalence estimates for the various dehydration classifications are shown in Table 2. Adjusting for sampling design, the weighted estimates for prevalences of hypotonic hypovolaemia, hypernatraemia, elevated BUN/creatinine, mildly and overtly elevated plasma tonicity were $0.6,3.5,12.2,36.5$ and 19.4\%, respectively. Overall, $61.6 \%$ of the subjects were dehydrated by one or more criteria, while $30.2 \%$ were classified as normal by all criteria. The remaining $8.3 \%$ had hypotonic or hyponatraemic plasma without orthostatic hypotension.

Table 1 Blood chemistry values for adults over 70 years of age who gave blood as part of the 1992 Established Populations for Epidemiologic Studies of the Elderly

\begin{tabular}{|c|c|c|c|c|c|c|c|c|}
\hline & $\begin{array}{c}\text { Total } \\
(n=1737)\end{array}$ & $\begin{array}{c}\text { Male } \\
(n=604)\end{array}$ & $\begin{array}{c}\text { Female } \\
(n=1113)\end{array}$ & $\begin{array}{c}\text { Black } \\
(n=926)\end{array}$ & $\begin{array}{c}\text { White } \\
(n=811)\end{array}$ & $\begin{array}{c}70-84 \text { years } \\
(n=1508)\end{array}$ & $\begin{array}{c}85+\text { years } \\
(n=229)\end{array}$ & $\begin{array}{l}\text { Normal } \\
\text { range }\end{array}$ \\
\hline $\mathrm{BUN}\left(\mathrm{mg} \mathrm{dl}^{-1}\right)$ & $19.0(8.5)$ & $18.7(7.8)$ & $19.2(8.9)$ & $19.2(9.9)$ & $18.9(6.6)$ & $18.9(8.6)$ & $20.2(8.0)^{\star \star}$ & $6-26$ \\
\hline Creatinine $\left(\mathrm{mg} \mathrm{dl}^{-1}\right)$ & $1.3(0$ & $1.5(0.7)$ & $1.3(0.5)^{\star *}$ & $1.4(0.7)$ & $1.2(0.3)^{\star *}$ & $1.3(0.6)$ & $1.3(0.4)$ & $0.7-1.5$ \\
\hline BUN/creatinine & $14.5(4.4)$ & $13.0(3.9)$ & $15.3(4.4)^{\star *}$ & $13.7(4.2)$ & $15.3(4.4)^{\star *}$ & $14.3(4.3)$ & $15.3(4.7)^{\star \star}$ & $8-20$ \\
\hline Sodium (mEql ${ }^{-1}$ ) & $140.2(2.8)$ & $140.0(2.6)$ & $140.3(2.9)^{\star}$ & $140.5(2.7)$ & $139.8(2.9)^{\star *}$ & $140.1(2.8)$ & $140.6(3.0)^{\star \star}$ & $137-145$ \\
\hline Glucose $\left(\mathrm{mg} \mathrm{dl}^{-1}\right)$ & $125.1(59.5)$ & $128.1(62.8)$ & $123.5(57.7)$ & $128.8(65.1)$ & $120.9(52.3)^{\star \star}$ & $126.4(61.5)$ & $116.7(43.5)^{\star *}$ & $70-110$ \\
\hline Potassium (mEq $\left.{ }^{-1}\right)$ & $4.2(0.5)$ & $4.3(0.5)$ & $4.2(0.5)^{\star *}$ & $4.2(0.5)$ & $4.3(0.5)^{\star \star}$ & $4.2(0.5)$ & $4.2(0.5)$ & $3.7-5.0$ \\
\hline Tonicity (mOsmi ${ }^{-1}$ ) & $295.8(5.7)$ & $295.8(5.4)$ & $295.8(5.9)$ & $296.5(5.3)$ & $295.0(5.9)^{\star \star}$ & 295.7 (5.6) & $296.1(6.1)$ & $285-295$ \\
\hline Albumin $\left(\mathrm{g} \mathrm{dl}^{-1}\right)$ & $4.1(0.4)$ & $4.2(0.3)$ & $4.1(0.4)$ & $4.1(0.4)$ & $4.2(0.3)^{\star \star}$ & $4.2(0.4)$ & $4.1(0.4)^{\star \star}$ & $3.5-4.5$ \\
\hline Haematocrit (\%) & $39.4(4.3)$ & $41.5(4.3)$ & $38.3(4.0)^{\star *}$ & $38.6(4.3)$ & $40.4(4.1)^{\star \star}$ & $39.6(4.3)$ & $38.0(4.4)^{\star \star}$ & $39-47$ \\
\hline
\end{tabular}

BUN - blood urea nitrogen.

Unweighted data, presented as mean (standard deviation).

Significance of differences for comparisons with the corresponding reference category (male sex, black race or age $70-84$ years): ${ }^{*}, P<0.10$, **, $P<0.05$. 
Table 2 Crude prevalence (\%) of dehydration or other fluid disorders by sociodemographic, health and functional status

\begin{tabular}{|c|c|c|c|c|c|c|c|c|}
\hline & \multirow[b]{2}{*}{$n$} & \multirow{2}{*}{$\frac{\text { BUN/creatinine }}{\geq 20}$} & \multicolumn{2}{|c|}{ Tonicity (mOsm I ${ }^{-1}$ ) } & \multirow{2}{*}{$\frac{\text { Sodium }\left(\mathrm{mEq} \mathrm{I}^{-1}\right)}{\geq 145}$} & \multirow{2}{*}{$\begin{array}{l}\text { Hypotonic } \\
\text { hypovolaemia† }\end{array}$} & \multirow[b]{2}{*}{ All typesł } & \multirow[b]{2}{*}{ Not dehydrated§ } \\
\hline & & & $295-300$ & $\geq 300$ & & & & \\
\hline Total & 1737 & 11.6 & 36.7 & 21.2 & 3.9 & 0.5 & 62.9 & 30.4 \\
\hline Male & 604 & 4.8 & 38.7 & 19.2 & 2.2 & 0.3 & 59.9 & 33.8 \\
\hline Female & 1133 & $15.3^{\star \star}$ & 35.7 & $22.3^{*}$ & $4.9^{\star}$ & 0.5 & $64.5^{\star}$ & $28.6^{\star \star}$ \\
\hline Black & 926 & 9.1 & 36.8 & 25.2 & 4.6 & 0.2 & 65.2 & 30.4 \\
\hline White & 811 & $14.6^{\star \star}$ & 36.6 & $16.8^{\star \star}$ & $3.1^{\star \star}$ & $0.7^{\star}$ & $60.3^{\star \star}$ & 30.5 \\
\hline \multicolumn{9}{|l|}{ Age (years) } \\
\hline $70-74$ & 586 & 8.7 & 36.7 & 20.8 & 3.9 & 0.2 & 61.4 & 32.1 \\
\hline $75-79$ & 535 & 10.8 & 37.9 & 19.4 & 3.4 & 0.9 & 62.4 & 30.8 \\
\hline $80-84$ & 387 & 14.2 & 32.6 & 23.5 & 3.1 & 0.5 & 61.5 & 31.3 \\
\hline $85-89$ & 168 & 15.5 & 37.5 & 21.4 & 6.0 & 0 & 66.7 & 26.2 \\
\hline $90+$ & 61 & $19.7^{\star \star}$ & 50.8 & $26.2^{*}$ & 8.2 & 0 & $80.3^{\star \star}$ & $16.4^{*}$ \\
\hline \multicolumn{9}{|c|}{ Chronic disease co-morbidity } \\
\hline$<2$ & 1012 & 11.2 & 37.6 & 18.0 & 3.6 & 0.5 & 60.9 & 32.9 \\
\hline$\geq 2$ & 725 & 12.3 & 35.6 & $25.8^{\star *}$ & $4.4^{\star \star}$ & 0.4 & $65.8^{\star *}$ & $26.9^{\star *}$ \\
\hline \multicolumn{9}{|l|}{ All cancer } \\
\hline Ever & 312 & 14.4 & 35.6 & 22.4 & 3.9 & 0.3 & 63.5 & 29.8 \\
\hline Never & 1425 & $11.0^{*}$ & 37.0 & 21.0 & 3.9 & 0.5 & 62.8 & 30.5 \\
\hline \multicolumn{9}{|l|}{ Heart disease } \\
\hline Ever & 376 & 11.4 & 34.8 & 23.7 & 6.9 & 0.5 & 62.5 & 31.4 \\
\hline Never & 1361 & 11.7 & 37.3 & 20.6 & $3.1^{\text {** }}$ & 0.4 & 63.0 & 30.1 \\
\hline \multicolumn{9}{|l|}{ Stroke } \\
\hline Ever & 200 & 9.5 & 38.5 & 23.5 & 3.0 & 0.5 & 65.5 & 29.0 \\
\hline Never & 1537 & 11.9 & 36.5 & 21.0 & 4.0 & 0.5 & 62.6 & 30.6 \\
\hline \multicolumn{9}{|l|}{ Diabetes } \\
\hline Ever & 408 & 12.3 & 38.0 & 33.8 & 3.2 & 0.3 & 75.0 & 16.7 \\
\hline Never & 1329 & 11.4 & 36.3 & $17.4^{\star \star}$ & $4.1^{\star \star}$ & 0.5 & $59.2^{\star \star}$ & $34.6^{\star \star}$ \\
\hline \multicolumn{9}{|l|}{ Hypertension } \\
\hline Ever & 1211 & 12.3 & 35.8 & 22.6 & 4.1 & 0.5 & 63.5 & 29.2 \\
\hline Never & 526 & 10.1 & 39.0 & $18.1^{\star \star}$ & $3.4^{*}$ & 0.4 & 61.6 & $33.3^{*}$ \\
\hline \multicolumn{9}{|c|}{ Plasma IL-6 $\left(\mathrm{pg} \mathrm{ml}^{-1}\right)$} \\
\hline$<5$ & 1519 & 11.7 & 37.3 & 21.8 & 3.8 & 0.3 & 63.9 & 29.6 \\
\hline \multirow{2}{*}{\multicolumn{9}{|c|}{ Prescriptions }} \\
\hline & & & & & & & & \\
\hline$<2$ & 704 & 9.9 & 39.4 & 19.2 & 3.4 & 0.3 & 63.4 & 31.4 \\
\hline$\geq 2$ & 1033 & $12.8^{*}$ & 35.0 & $22.7^{\star \star}$ & $4.3^{\star \star}$ & 0.6 & 62.6 & 29.7 \\
\hline \multicolumn{9}{|l|}{ Weight status } \\
\hline Underweight & 72 & 23.6 & 41.7 & 18.1 & 4.2 & 2.8 & 70.8 & 27.8 \\
\hline Normal & 702 & 11.8 & 34.5 & 19.0 & 4.0 & 0.4 & 59.3 & 32.3 \\
\hline Overweight & 683 & 9.5 & 36.8 & 21.2 & 3.2 & 0.3 & 61.9 & 31.6 \\
\hline Obese & 330 & $12.7^{\star \star}$ & 40.3 & $27.0^{\star \star}$ & 5.2 & $0.3^{\star \star}$ & $70.9^{\star \star}$ & $24.6^{*}$ \\
\hline \multicolumn{9}{|c|}{ Rosow-Breslau score } \\
\hline 0 & 820 & 9.5 & 38.2 & 17.7 & 2.9 & 0.1 & 60.6 & 33.2 \\
\hline$>0$ & 917 & $13.5^{\star \star}$ & 35.4 & $24.4^{\star \star}$ & $4.8^{\star \star}$ & $0.8^{\star *}$ & $65.0^{*}$ & $27.9^{\star \star}$ \\
\hline
\end{tabular}

BUN - blood urea nitrogen; IL - interleukin.

All values are crude unweighted prevalences (weighted values are reported in the text), expressed as \%.

Significance of differences for comparisons (chi-square test) with the corresponding reference category (male sex, black race, age $70-84$ years, normal plasma IL-6, normal weight status, no history of chronic disease co-morbidity, cancer, heart disease, stroke, diabetes, hypertension, poly-pharmacy or functional disability): * $P<0.10,{ }^{* *}, P<0.05$.

† Subjects with plasma tonicity $<285 \mathrm{mOsm} \mathrm{I}^{-1}$ who experienced a change in diastolic blood pressure from sitting to standing greater than $10 \mathrm{mmHg}$.

$\ddagger$ Plasma BUN/creatinine $\geq 20$ or tonicity $\geq 295 \mathrm{mOsm} \mathrm{I}^{-1}$ or sodium $\geq 145 \mathrm{mEq} \mathrm{I}^{-1}$ or hypotonic hypovolaemia.

§ Subjects who had plasma BUN/creatinine $<20$ and tonicity $\geq 285$ to $<295 \mathrm{mOsm} \mathrm{I}^{-1}$ and sodium $\geq 137$ to $^{2} 145 \mathrm{mEq} \mathrm{I}^{-1}$ were considered non-dehydrated.

The values listed in the 'all types' and 'not dehydrated' columns do not sum to $100 \%$, because 120 subjects were hyponatraemic (i.e. abnormal) but not hypovolaemic (i.e. not dehydrated).

I Underweight - body mass index $(\mathrm{BMI})<18.5 \mathrm{~kg} \mathrm{~m}^{-2}$; normal weight $-\mathrm{BMI} \geq 18.5$ to $<25.0 \mathrm{kgm}^{-2}$; overweight $-\mathrm{BMI} \geq 25.0$ to $<30.0 \mathrm{~kg} \mathrm{~m}{ }^{-2}$; obese $\mathrm{BMI} \geq 30.0 \mathrm{~kg} \mathrm{~m}^{-2}$.

We observed little overlap between the indices (see Table 3). Only 3\% of the sample had hypertonic plasma and an elevated BUN/creatinine ratio. Half the sample had a normal BUN/creatinine, but an elevated plasma tonicity. The kappa statistic, evaluating agreement between the tonicity- and BUN/creatinine-based classifications (dehydrated/not dehydrated), was 0.01 (95\% CI: $-0.01,0.04, P=0.15)$. Many subjects with an elevated plasma tonicity were not classified as hypernatraemic (kappa $=0.06,95 \%$ CI: 0.04, 0.07, $P<0.001$ ). Given the low prevalence of hypotonic hypovolaemia and hypernatraemia in this sample, and that all hypernatraemic subjects were hypertonic, the remaining analysis focused on tonicity and BUN/creatinine status only.

To get a sense of whether the BUN/creatinine- and tonicity-based estimates might reflect disorders other than 
Table 3 Comparison of three indices of fluid status (plasma BUN/creatinine, tonicity and sodium): weighted estimates of the prevalence (\%) of dehydration among adults over 70 years of age who gave blood as part of the 1992 Established Populations for Epidemiologic Studies of the Elderly

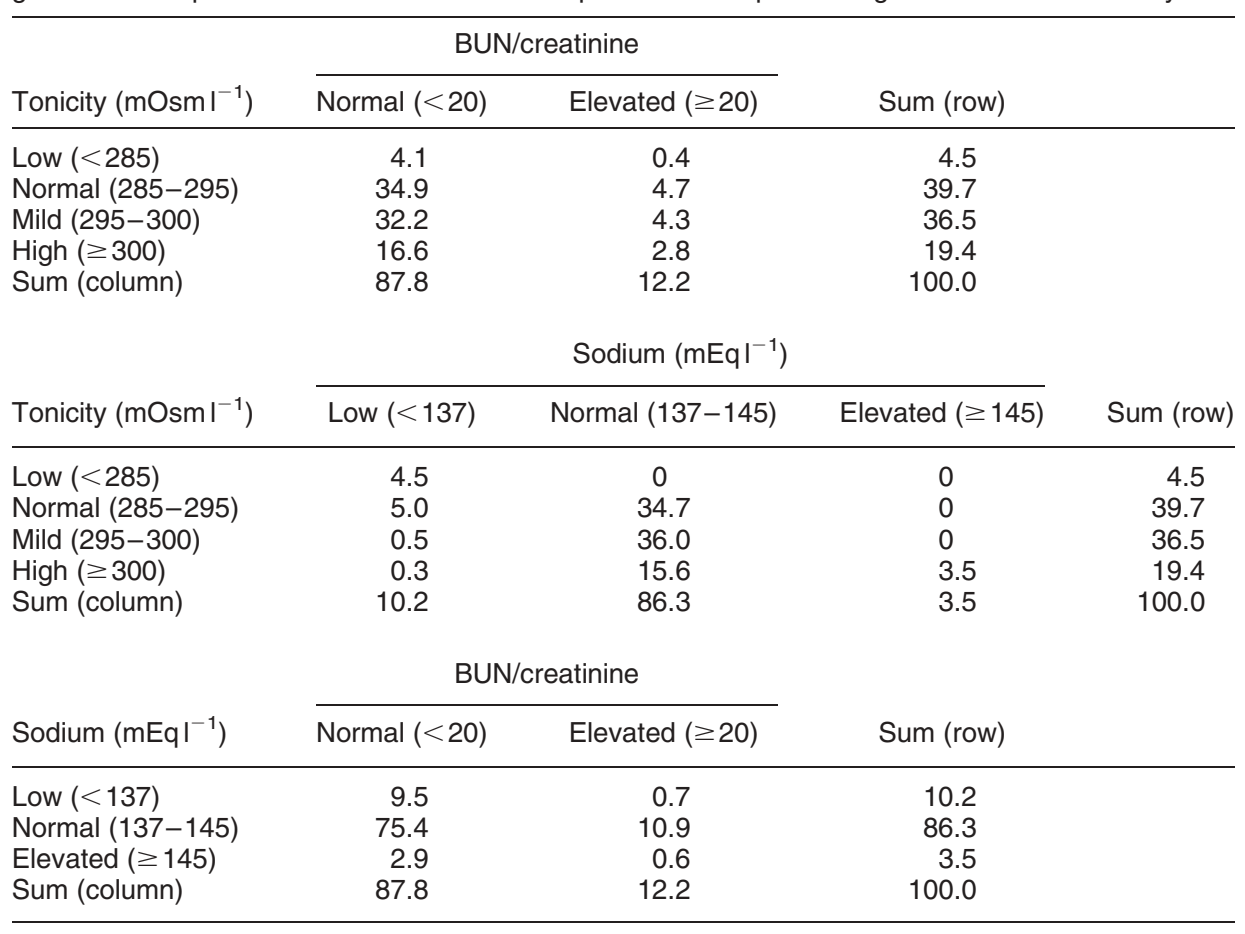

BUN - blood urea nitrogen.

underhydration, we examined the blood chemistry measures shown in Table 4. Compared with normal plasma tonicity, elevated plasma tonicity was associated with significantly greater likelihood of above-normal plasma glucose, BUN and albumin values. Plasma glucose exceeded the standard cut-off for diabetes $\left(200 \mathrm{mg} \mathrm{dl}^{-1}\right)$ for approximately a quarter of the overtly hypertonic subjects. Plasma glucose values between 140 and $200 \mathrm{mg} \mathrm{dl}^{-1}$ (which are considered abnormal following a 2-hour oral glucose tolerance test) suggested glucose intolerance for approximately $15 \%$ of the hypertonic group ${ }^{20}$. The apparent positive trend between plasma potassium and tonicity was not statistically significant. Consistent with plasma tonicity as an index of haemoconcentration and underhydration, significant linear trends were observed between tonicity, haematocrit and creatinine.

Having an elevated BUN/creatinine ratio was associated with above-normal potassium and BUN values. The relatively low mean creatinine, albumin and haematocrit values for this group did not indicate haemoconcentration.

Subjects who were classified as normal by one measure, but dehydrated by another, differed significantly from those classified as non-dehydrated by both indices. Normotonic subjects with an elevated BUN/creatinine ratio were significantly less likely to have elevated plasma glucose, creatinine, albumin and haematocrit values, and more likely to have an elevated BUN than the group with both normal tonicity and BUN/creatinine values. Subjects with a normal BUN/creatinine ratio but elevated plasma tonicity were more likely to have elevated glucose and albumin levels.

The subjects classified as dehydrated by both indices were more likely to have abnormal plasma glucose, creatinine, BUN and haematocrit values than normotonic subjects with an elevated BUN/creatinine, and more likely to have abnormal potassium, BUN and haematocrit values than subjects with a normal BUN/creatinine but an elevated plasma tonicity.

Figure 1 illustrates the prevalence of each fluid status type by age, sex and race, weighted for survey design, as well as adjusted for age, sex and race. Age and female sex were positively associated with elevated BUN/creatinine status. Blacks were more likely to be hypertonic, and less likely to have an elevated BUN/creatinine than whites.

Elevated plasma tonicity and BUN/creatinine status were disproportionately distributed among subjects with chronic disease and functional impairment (see Table 5). Compared with normotonic subjects, the overtly hypertonic subjects were significantly more likely to report co-morbidity, diabetes, hypertension, obesity and functional impairment. Subjects with a plasma tonicity greater than $300 \mathrm{mOsm}^{-1}$ were twice as likely to be obese, and three times as likely to be diabetic. Mildly elevated plasma tonicity was associated with 70 and $80 \%$ increases in the risk of diabetes and obesity. A slight trend towards increased risk of stroke with increasing plasma tonicity 
(a)

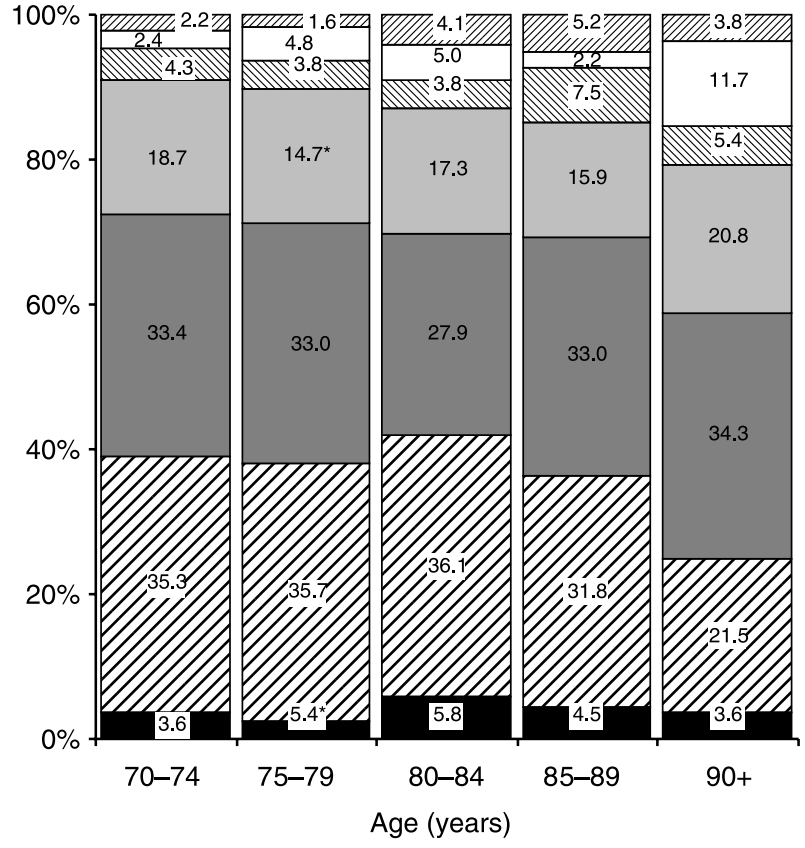

(b)

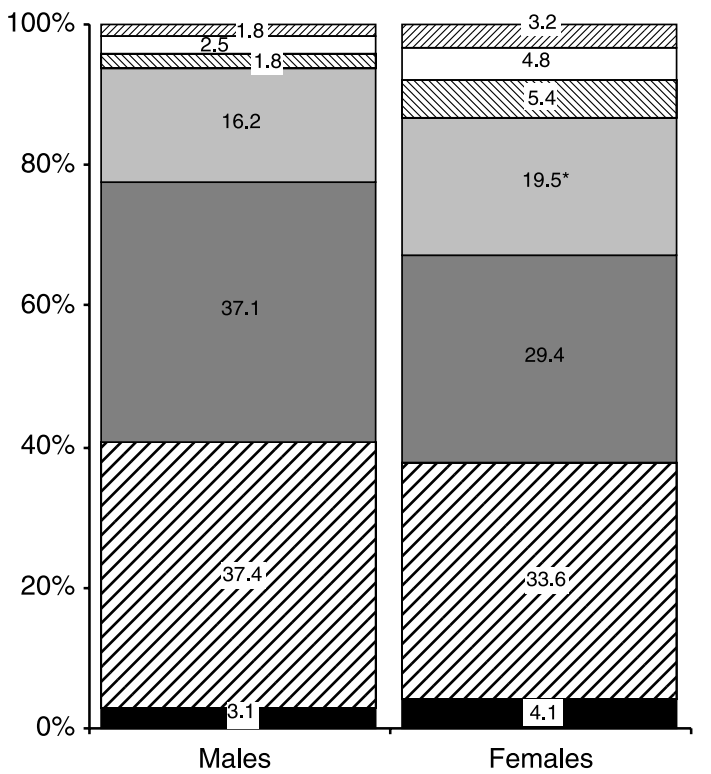

Elevated BUN/C, high tonicity

Elevated BUN/C, mild tonicity

Elevated BUN/C, normal tonicity

Normal BUN/C, high tonicity (c)

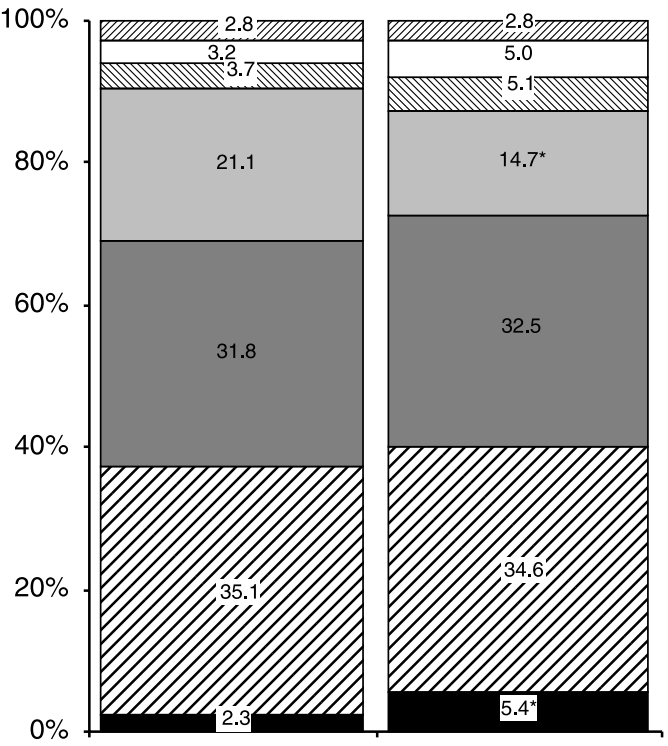

Blacks

Whites

Normal BUN/C, mild tonicity

$\square$ Normal BUN/C, normal tonicity

Low tonicity

Fig. 1 Adjusted age- (a), sex- (b) and race-specific (c) weighted estimates of the prevalence of dehydration among adults over 70 years of age who gave blood as part of the 1992 Established Populations for Epidemiologic Studies of the Elderly. Estimates were predicted from a multinomial logistic model predicting fluid status group, adjusting for age, sex, race, plasma creatinine and survey design. Elevated BUN/C - blood urea nitrogen/creatinine ratio $\geq 20$; low tonicity - tonicity $<285 \mathrm{mOsm} \mathrm{I}^{-1}$; normal tonicity - tonicity $\geq 285$ to $<295 \mathrm{mOsm} \mathrm{I}^{-1}$; mild tonicity - tonicity $\geq 295$ to $<300 \mathrm{mOsml}^{-1}$; high tonicity - tonicity $\geq 300 \mathrm{mOsml}^{-1}$. ${ }^{*} P$-value $<0.05$ for comparison with corresponding value among males, blacks, or the youngest age group 


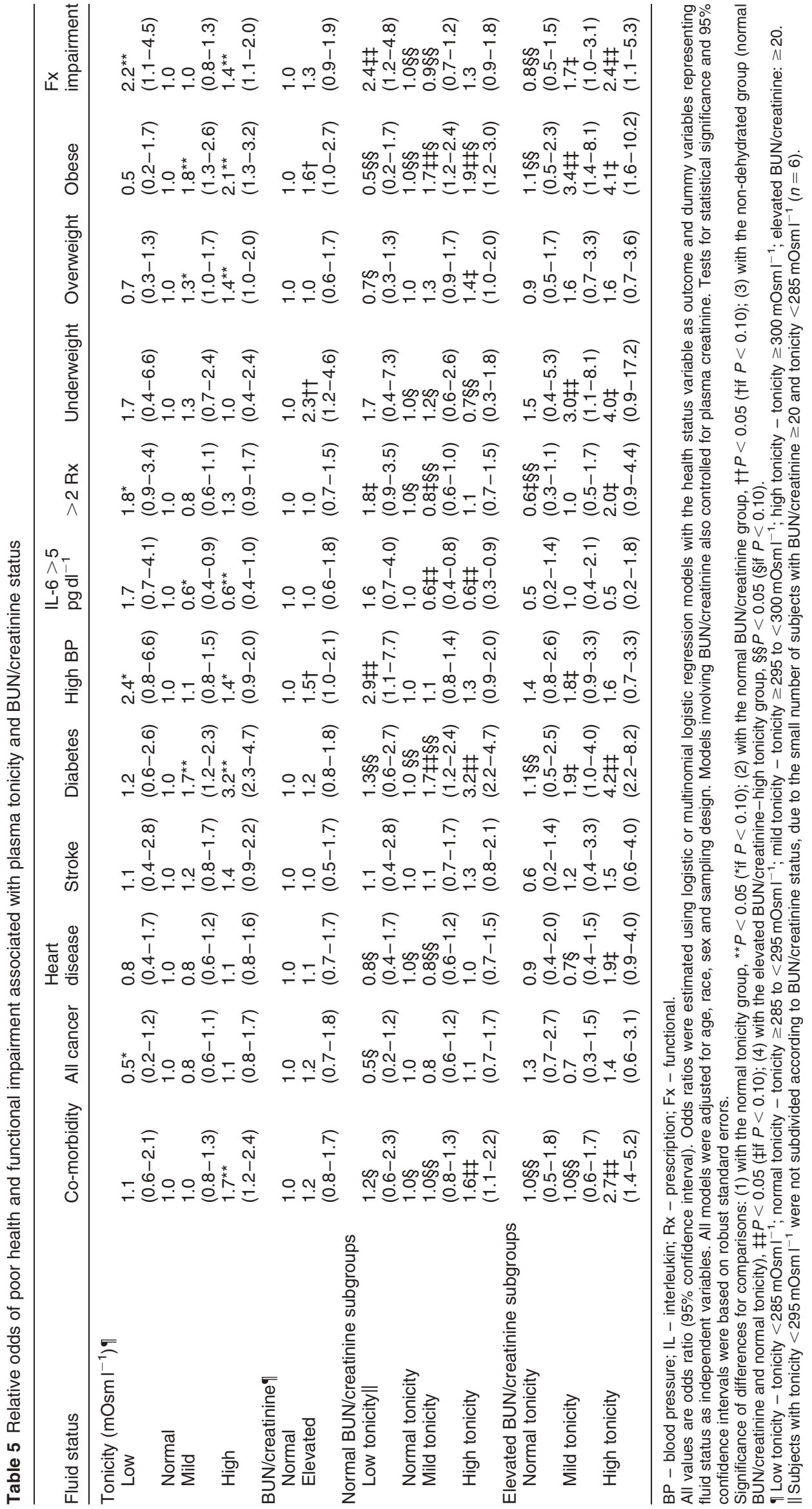


was not statistically significant. Significant U-shaped associations were observed between plasma tonicity and poly-pharmacy and functional impairment. Elevated plasma IL-6 was negatively associated with plasma tonicity. Relative to normal BUN/creatinine, elevated BUN/creatinine was associated with a 50\% increase in the risk of hypertension and obesity, and a two-fold increase in the risk of underweight. Elevated BUN/creatinine status appeared to modify the magnitude of the association between elevated plasma tonicity and health. Significantly stronger associations were observed for hypertonic subjects with an elevated BUN/creatinine ratio.

\section{Discussion}

A range of estimates for the prevalence of dehydration was observed for this large representative sample of community-dwelling adults aged 70 years and over. Consistent with the estimates from previous community-based studies, we report prevalences of hypotonic hypovolaemia and hypernatraemia of less than $5 \%{ }^{12-14}$, as well as a prevalence of elevated BUN/creatinine ratio of approximately $10 \%{ }^{12,13}$. The data also suggest, however, that the prevalence of dehydration could range as high as 60\%, if other forms of dehydration are included in the estimate. The highest prevalence was observed when dehydration was defined as hypotonicity with orthostatic hypotension, serum sodium, elevated BUN/creatinine ratio, or elevated plasma tonicity. Only $30 \%$ of the sample could be considered non-dehydrated when all criteria were evaluated simultaneously.

The indices and cut-offs employed in this study, commonly used in the literature, although may only reflect particular facets of dehydration. Plasma sodium and $\mathrm{BUN} /$ creatinine ratio the index hydration status relative to solute load. Plasma tonicity indexes cellular hydration status and vasopressin response ${ }^{19,24}$. Dehydration may be defined in terms of a wide variety of indices, inadequate body water for the maintenance of optimal biochemical, cellular, physiological function or health - under normal conditions or those which raise fluid requirements (e.g. illness, pregnancy, altitude and heat $)^{25}$. Given the variety of possible criteria for defining adequate hydration, the lack of overlap or agreement between measures in this study is not surprising. No single measure has yet been identified that can fully discriminate between dehydrated and nondehydrated persons. These and previous results highlight the need for a set of indicators ${ }^{15,26}$. Prevalence estimates derived from plasma sodium, BUN/creatinine or tonicity alone may not tell us the whole story about dehydration.

The available measures may reflect different gradations of dehydration severity. Indicators involving blood pressure, extracellular blood volume or functional performance may be relatively insensitive to mild dehydration. Compensatory mechanisms can allow vital physiological systems and physical performance to be maintained despite loss of body water. Worsening dehydration is known to be associated with increasingly severe outcomes $^{27}$. While agreement across several indicators might maximise confidence in the classification of individuals as dehydrated, the relative insensitivity of some indicators to mild dehydration could result in mildly dehydrated individuals being misclassified as non-dehydrated. In the present study, subjects classified as dehydrated according to multiple criteria appeared worse off in terms of health status than other subjects. The use of multiple indicators may allow detection of mild as well as severe dehydration.

O'Neill et $a l^{28}$ argue that every study of water depletion should evaluate plasma tonicity. Others argue that plasma sodium is not a substitute measure for plasma tonicity ${ }^{26}$. Fluid and electrolyte textbooks and several other authors also recommend plasma hypertonicity as an indicator of underhydration $^{19,29}$. Despite these recommendations, previous community-based studies did not evaluate plasma tonicity ${ }^{13}$. Inferences about the overall hydration status and fluid recommendations for older adults were drawn from results specific to hypernatraemic dehydration. O'Neill et al. ${ }^{28}$ may be correct that hypernatraemic dehydration is only a thin end of a large wedge.

Estimating the overall prevalence of dehydration is complicated by several factors. Aside from the variety of possible indicators, available indicators are not specific for dehydration. Indices may reflect fluid disorders or pathologies other than dehydration, as well as side-effects of drugs, such as hypertension medication. The low haematocrit, creatinine and albumin values and lack of orthostatic hypotension observed among subjects with an elevated BUN/creatinine ratio suggest renal dysfunction or congestive heart failure. Abnormal water metabolism related to sarcopenia or autonomic neuropathy might also have influenced the BUN/creatinine ratio. Although traditionally advocated for hydration assessment, validation data are lacking for this and other commonly used measures ${ }^{15}$.

Validation data are needed to confirm a high prevalence of hypertonicity. The validity of hypertonicity indicators depends on the ability of plasma solute to permeate cell membranes, which varies with hormone status ${ }^{30}$. Equations that include permeable solute or exclude impermeable solute may over- or underestimate tonicity, respectively. Although values of plasma tonicity above $300 \mathrm{mOsm}^{-1}$ are recognised as indicative of cellular dehydration $^{19,24,29,31}$, data on the sensitivity and specificity of available equations and cut-offs are lacking. Evidence of haemoconcentration suggests that hypertonicity reflects significant underhydration in this group. If estimated plasma tonicities above $295 \mathrm{mOsml}^{-1}$ accurately reflect dehydration, then dehydration may affect a majority of older adults.

The large prevalence of elevated plasma tonicity may reflect transiently elevated postprandial glucose levels or a high prevalence of glucose intolerance among older adults. Plasma hypertonicity was associated with elevated 
plasma glucose and diabetes risk in this study. Although plasma tonicity was estimated from non-fasting blood values, the prevalence of elevated plasma glucose in this sample is consistent with the high prevalence of glucose intolerance in representative samples of older adults in the USA, Europe and Asia ${ }^{32-35}$.

Elevated plasma tonicity was positively associated with chronic disease co-morbidity, diabetes, hypertension, obesity, functional impairment, older age, female sex and black race. Elevated BUN/creatinine status was positively associated with hypertension, abnormal weight status, older age, female sex and white race. These associations imply that the observed prevalence of dehydration could reflect the prevalence and distribution of chronic disease and disability, and/or the sociodemographic profile of this sample. Older age and female sex are associated with the frail phenotype $e^{36}$. Black race is associated with increased risk of diabetes, obesity and related chronic diseases.

Age-related declines in organ function and appetite, illness and disability and increased fluid requirements predispose older adults to dehydration ${ }^{1,4-7}$. If the elevated plasma tonicity and/or BUN/creatinine observed in this study is attributable to ageing, illness and/or disability, then, as suggested by Lindeman et al. ${ }^{13}$, dehydration might only be a problem for the oldest, most frail and infirm elders. Given the cross-sectional nature of the present results, however, it is possible that the elevated plasma tonicity or BUN/creatinine pre-dated the development of disease. Research to identify the temporal sequence of the observed effects is needed to inform fluid recommendations for community-dwelling older adults.

The true prevalence of dehydration for this sample could be anywhere from $1 \%$ to $60 \%$, depending on the definition of dehydration, measurement errors, and the underlying distribution of illness and functional impairment. This wide range suggests that while the prevalence of dehydration for community-dwelling older adults could really be low, it may also be quite high, with markedly different implications for fluid intake recommendations. Validation studies of the available dehydration indices - particularly estimated plasma tonicity - and longitudinal studies to characterise the magnitude and direction of associations between hypertonicity and health and functional status are needed before we can pinpoint a generalisable prevalence of dehydration for community-dwelling older adults. It may be premature to draw conclusions about fluid recommendations from available prevalence estimates.

\section{Acknowledgements}

This work was supported by contract NO1 AG-12 102 from the National Institute on Aging (NIA), a grant (\#1R01 AG12765) from the National Institutes of Health's Established Populations for Epidemiologic Studies of the
Elderly, a Claude D Pepper Center grant (\#AG11268), as well as NIA grant \#AG00029.

\section{References}

1 Lavizzo-Mourey RJ. Dehydration in the elderly: a short review. Journal of the National Medical Association 1987; 79(10): 1033-8.

2 Phillips PA, Rolls BJ, Ledingham JGG, Forsling ML, Morton JJ, Crowe MJ, et al. Reduced thirst after water deprivation in healthy elderly men. New England Journal of Medicine 1984; 311(12): 753-9

3 Rowe JW, Andres R, Tobin JD, Norris AH, Shock NW. The effect of age on creatinine clearance in men: a crosssectional and longitudinal study. Journal of Gerontology 1976; 31(2): 155-63.

4 Silver AJ. Aging and risks for dehydration. Cleveland Clinic Journal of Medicine 1990; 57(4): 341-4.

5 Leaf A. Dehydration in the elderly. New England Journal of Medicine 1984; 311(12): 791-2.

6 Hoffman NB. Dehydration in the elderly: insidious and manageable. Geriatrics 1991; 46(6): 35-8.

7 Lavizzo-Mourey R, Johnson J, Stolley P. Risk factors for dehydration among elderly nursing home residents. Journal of the American Geriatrics Society 1988; 36(3): 213-8.

8 US Department of Agriculture (USDA). The Food Guide Pyramid. Home and Garden Bulletin No. 252. Washington, DC: USDA Human Nutrition Information Service, 1992.

9 Russell RM, Rasmussen H, Lichtenstein AH. Modified food guide pyramid for people over seventy years of age. Journal of Nutrition 1999; 129(3): 751-3.

10 O'Neill PA, Davies I, Wears R, Barrett JA. Elderly female patients in continuing care: why are they hyperosmolar? Gerontology 1989; 35(4): 205-9.

11 Weinberg AD, Pals JK, Levesque PG, Beal LF, Cunningham TJ, Minaker KL. Dehydration and death during febrile episodes in the nursing home. Journal of the American Geriatrics Society 1994; 42(9): 968-71.

12 Miller D, Perry HM, Morley JE. Relationship of dehydration and chronic renal insufficiency with function and cognitive status in older US blacks. In: Vellas B, Albarede JL, Garry PJ, eds. Hydration and Aging. New York: Springer Publishing Company, 1998; 149-59.

13 Lindeman RD, Romero LJ, Liang HC, Baumgartner RN, Koehler KM, Garry PJ. Do elderly persons need to be encouraged to drink more fluids? Journals of Gerontology Series A, Biological Sciences and Medical Sciences 2000; 55(7): M361-5.

14 Caird FI, Andrews GR, Kennedy RD. Effect of posture on blood pressure in the elderly. British Heart Journal 1973; 35(5): 527-30.

15 Rikkert MO, Hoefnagels W, Deurenberg P. Age-related changes in body fluid compartments and the assessment of dehydration in old age. In: Vellas B, Albarede JL, Garry PJ, eds. Hydration and Aging. New York: Springer Publishing Company, 1998; 9-32.

16 Weinberg AD, Minaker KL. Council on Scientific Affairs, American Medical Association. Dehydration, evaluation and management in older adults. Journal of the American Medical Association 1995; 274(19): 1552-6.

17 Pieper CF, Rao KM, Currie MS, Harris TB, Chen HJ. Age, functional status, and racial differences in plasma D-dimer levels in community-dwelling elderly persons. Journals of Gerontology. Series A, Biological Sciences and Medical Sciences 2000; 55(11): M649-57.

18 Cohen HJ, Pieper CF, Harris T, Rao KMK, Currie MS. The association of plasma IL-6 levels with functional disability in community-dwelling elderly. Journals of Gerontology. 
Series A, Biological Sciences and Medical Sciences 1997; 52(4): M201-8.

19 Matz R. Dehydration in older adults. Journal of the American Medical Association 1996; 275(12): 911-2.

20 American Diabetes Association. Diagnosis and lab tests [online]. Available at http://www.diabetes.org/main/type1/ medical/lab/diagnosis.jsp. Accessed December 2002.

21 World Health Organization (WHO) Expert Committee. Physical Status: The Use and Interpretation of Anthropometry. WHO Technical Report Series No. 854. Geneva: WHO, 1995.

22 Rosow I, Breslau N. A Guttman health scale for the aged. Journal of Gerontology 1966; 21(4): 556-9.

23 StataCorp. Stata Statistical Software, Release 6.0. College Station, TX: Stata Corporation, 1999.

24 Gennari FJ. Current concepts, serum osmolality, uses and limitations. New England Journal of Medicine 1984; 310(2): $102-5$.

25 National Research Council. Recommended Dietary Allowances, 10th ed. Washington, DC: National Academy of Sciences, 1989; 249.

26 Weinberg AD, Pals JK, McGlinchey-Berroth R, Minaker KL. Indices of dehydration among frail nursing home patients: highly variable but stable over time. Journal of the American Geriatrics Society 1994; 42(10): 1070-3.

27 Greenleaf JE. Stress, aging and thirst. In: Vellas B, Albarede JL, Garry PJ, eds. Hydration and Aging. New York: Springer Publishing Company, 1998; 47-57.

28 O’Neill PA, Davies J, Morris J, McLean KA. Hypernatraemic dehydration in patients in a large hospital for the mentally handicapped. British Medical Journal 1990; 300(6721): $396-7$.
29 Halperin ML, Goldstein MB. Fluid, Electrolyte, and Acid-Base Physiology. Philadelphia, PA: WB Saunders Company, 1999.

30 Vokes TP, Aycinena PR, Robertson GL. Effect of insulin on osmoregulation of vasopressin. American Journal of Physiology 1987; 252(4 Pt 1): E538-48.

31 Star RA. Southwestern internal medicine conference: hyperosmolar states. American Journal of Medical Science 1990; 300(6): 402-12.

32 Pozefsky T, Colker JL, Langs HM, Andres R. The cortisone-glucose tolerance test: the influence of age on performance. Annals of Internal Medicine 1965; 63(6): 988-1000.

33 Teuscher AU, Reinli K, Teuscher A. The SENECA Investigators (Survey in Europe on Nutrition and the Elderly, a Concerted Action). Glycaemia and insulinaemia in elderly European subjects ( $70-75$ years). Diabetic Medicine 2001; 18(2): $150-3$.

34 Choi KM, Lee J, Kim DR, Kim SK, Shin DH, Kim NH, et al. Comparison of ADA and WHO criteria for the diagnosis of diabetes in elderly Koreans. Diabetic Medicine 2002; 19(10): $853-7$.

35 Resnick HE, Shorr RI, Kuller L, Franse L, Harris TB. Prevalence and clinical implications of American Diabetes Association-defined diabetes and other categories of glucose dysregulation in older adults: the health, aging and body composition study. Journal of Clinical Epidemiology 2001; 54(9): 869-76.

36 Fried LP, Walston J. Frailty and failure to thrive. In: Hazzard WR, Blass JP, Ettinger WH, et al., eds. Principles of Geriatric Medicine and Gerontology, 4th ed. New York: McGraw-Hill, 1999; $1387-402$. 